\title{
Reconocimiento y garantías del derecho a un ambiente sano y ecológicamente equilibrado
}

Sergio Emilio Castillo Torres* http://dx.doi.org/10.21503/lex.v10i9.332

Ms. C. Profesor Asistente de Derecho Constitucional. Facultad de Derecho de la Universidad de Guantánamo.

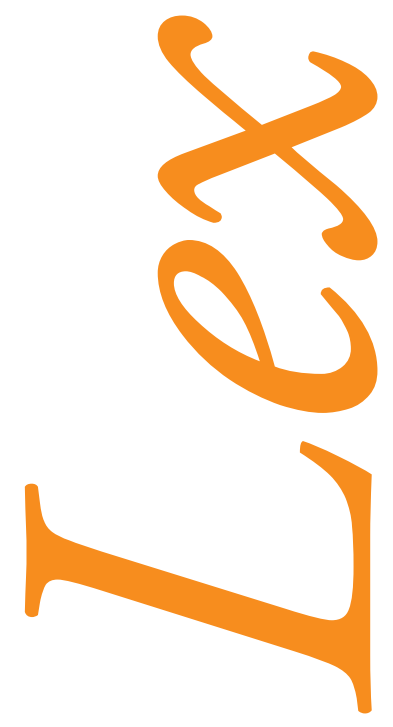




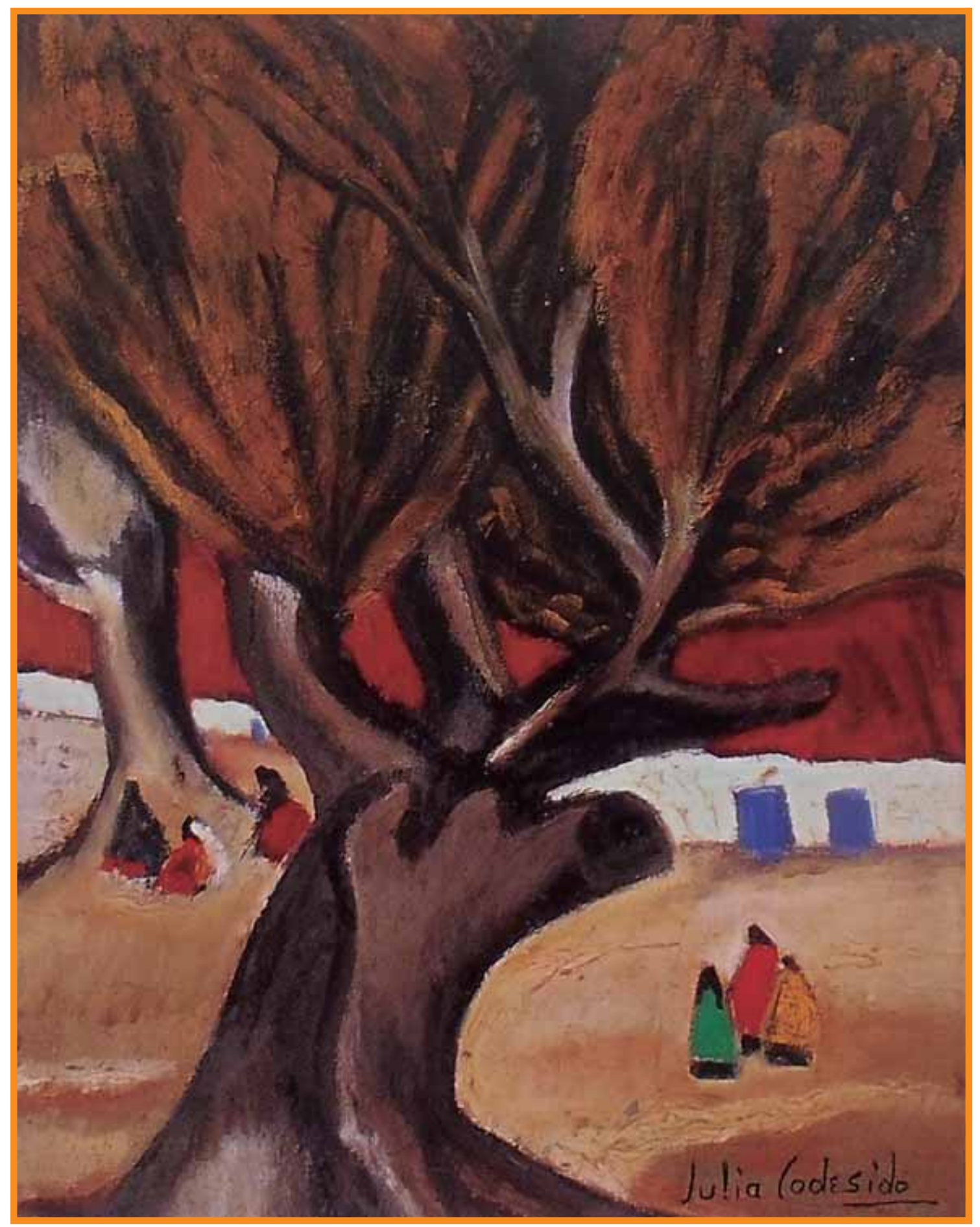

Pisonay. Colección particular. 


\section{Resumen}

La problemática ambiental es uno de los grandes temas en la vida política y social de cualquier país en la actualidad; en tal sentido, uno de los desafíos teóricos más relevantes que ha debido abordar el Derecho como ciencia es tratar de dar respuesta a las siguientes interrogantes: ¡es el derecho a vivir en un ambiente sano y ecológicamente equilibrado un derecho humano reconocido como tal?, ¿existe en la actualidad una adecuada tutela jurídica de este derecho? Son dos de las interrogantes que en el orden problémico nos condujeron a la realización del presente trabajo.

Y es que si bien el reconocimiento del derecho a un ambiente sano, como derecho humano de tercera generación, goza de amplio consenso a nivel mundial, aún dicho proceso no está del todo concluido, y en algunos países por ejemplo no goza de refrendo constitucional, situación esta que se debe tal vez, entre otras razones, a que la preocupación por el ambiente es relativamente reciente; de ahí que estudiosos del tema hace ya algún tiempo insisten en la necesidad de que además de consagrarse como un derecho humano tenga reconocimiento formal, tanto en el ámbito normativo internacional como en el nacional.

A partir de todas estas interrogantes nos trazamos como problema cientifico el siguiente: ¿garantizan hoy los ordenamientos jurídicos el derecho ciudadano a un ambiente sano y ecológicamente equilibrado?

Sobre esta base, nos formulamos como objetivo general fundamental de nuestro trabajo la necesidad, en primer lugar, del reconocimiento constitucional del derecho a un ambiente sano y ecológicamente equilibrado, y en un segundo momento el perfeccionamiento de las vías procesales dirigidas a su tutela judicial efectiva, en tanto consideramos que en la actualidad las vías de tutela empleadas no son las más efectivas. 


\section{El derecho a un ambiente sano y ecológicamente equilibrado. Origen histórico y clasificación doctrinal}

En las últimas décadas se ha producido un vertiginoso desarrollo de las ideas en torno al tema de los derechos humanos, a partir del cual han proliferado expresiones normas, instituciones y modelos de conductas. Estudiosos del tema lo han denominado como "el fenómeno de los derecho humanos". Ciertamente, tal fenómeno no ha surgido de la nada, sino que es el resultado de un pasado común de toda la humanidad, en cuanto los derechos humanos han estado presentes en las principales tendencias del pensamiento. Aunque tiene su raíz en el pasado, este fenómeno está íntimamente unido al surgimiento del constitucionalismo.

Los derechos humanos surgen históricamente como derechos civiles y políticos. Es la primera forma de aparición de los derechos humanos. Por eso se les denomina también, desde la perspectiva actual, derechos de primera generación.

En su origen, en el siglo XVIII, reciben varios nombres, tales como derechos individuales, derechos innatos, derechos esenciales y derechos del hombre y del ciudadano.

En su origen, los derechos individuales -que es como se denomina a los derechos positivizados-son concebidos como la expresión de los derechos innatos o derechos esenciales del que era portador el hombre en su estadio primitivo. La aparición de la organización política de la sociedad, acto también denominado por algunos pensadores de la filosofía clásica burguesa como contrato o pacto social, ${ }^{1}$ supuso la entrada del hombre en sociedad, y en consecuencia lo que se hace es reconocer, reforzar y garantizar esos derechos preexistentes.

Ante todo, se trata de proclamar, a través de estos derechos, la facultad de hacer de todo ser humano frente al Estado; dicho de otro modo, se puede decir que los derechos civiles suponen la exigencia de los particulares frente al poder del Estado, de la exclusión de su actuación. Por ello se les ha llamado "derechos de autonomía”, en tanto los derechos políticos suponen la posibilidad de participación de los ciudadanos en la formación de la voluntad política del Estado a través del derecho de sufragio. Por eso se les ha denominado "derechos de participación".

No es hasta principios del siglo XX que aparecen los derechos socioeconómicos y culturales, también denominados de segunda generación, encontrando a partir de entonces su refrendo constitucional. Pero la posibilidad de disfrute de estos derechos tuvo como antecedente causal la necesidad de un actuar positivo del modelo liberal en crisis, motivado principalmente

\footnotetext{
Las principales teorías relativas al contrato social fueron expuestas por los pensadores ingleses Thomas Hobbes y John
} Locke, y por el filósofo francés Jean-Jacques Rousseau. 
por las enormes diferencias sociales que creó y el nivel insoportable de explotación de las grandes masas trabajadoras, que unido a las luchas del proletariado contra el sistema existente obligaron a los Estados burgueses a implementar con urgencia un reacomodo de su hegemonía para de esa manera evitar el fin del sistema capitalista.

Entre los derechos de segunda generación o de prestación podemos mencionar el derecho al trabajo (libre elección del mismo, salario mínimo, derecho a las vacaciones y otros elementos), derecho a la seguridad social y a la asistencia social (derecho a la jubilación, a recibir prestaciones del Estado por diferentes causas, etc.), derecho a la salud (crear un sistema de salud gratuito u otras vías que posibiliten el acceso de todos a los servicios de salud), derecho a la educación, derecho a la cultura, entre los más importantes.

A los derechos civiles y políticos (de primera generación) y los derechos económicos, sociales y culturales (de segunda generación) vinieron a sumarse, a finales de los años 60 , un conjunto de derechos denominados de tercera generación, a los que también se les ha llamado derechos de los pueblos o de la solidaridad, que incluyen el derecho a la autodeterminación, a la paz, al desarrollo, a la democracia, a la integración, a la información, a la libre determinación, a beneficiarse del patrimonio común de la humanidad, además del derecho a un ambiente sano y ecológicamente equilibrado, entre otros, los cuales se corresponden con el auge del ecologismo y el pacifismo y con la creciente valoración de la tolerancia como condición indispensable para la convivencia humana.

La viabilidad del reconocimiento de una tercera generación en los derechos humanos fue sugerida por el profesor Karel Vasak, ${ }^{2}$ en 1977, partiendo de la evolución reciente de la sociedad humana, que exigía la aparición de nuevos derechos que bien podrían llamarse de tercera categoría o como "derechos humanos de tercera generación", según lo había sugerido recientemente el Director General de la UNESCO.

Estos derechos corresponden, como la doctrina lo ha interpretado, a las nuevas necesidades del hombre y de la colectividad humana en el actual grado de su desarrollo y evolución, y se estructuran sobre el sentido común de solidaridad humana. Recuérdese que la Asamblea General de la ONU aprobó, en 1989, la resolución sobre Derechos Humanos Fundados en la Solidaridad.

La tercera generación se inspira, como ya lo enunciara Karel Vasak, en una cierta concepción de la vida humana en comunidad, y tales derechos, según él, solo pueden ponerse en práctica

Las tres generaciones de derechos humanos fue una propuesta de Karel Vasak en 1979 para clasificar los derechos humanos. Su división sigue las nociones centrales de las tres frases que fueron la divisa de la Revolución Francesa: libertad, igualdad y fraternidad. Los capítulos de la Carta de los Derechos Fundamentales de la Unión Europea reflejan este esquema. 
gracias al esfuerzo conjunto de todos: desde los individuos y los Estados hasta las entidades y órganos públicos y privados.

Sobre esta nueva categoría de derechos, Héctor Gros comentó hace algunos años que estos derechos jurídicamente pueden considerarse en estado naciente, que surgen tanto en el Derecho Interno como en el Derecho Internacional y se caracterizan por exigir para su conceptualización un mayor grado de solidaridad que los otros derechos, por el hecho de ser al mismo tiempo derechos individuales y derechos colectivos. ${ }^{3}$

El Instituto Hispano-Luso-Americano de Derecho Internacional sustentó la necesidad de la aprobación de estos nuevos derechos en la evolución de la sociedad y del Derecho, reconociendo, además, su unidad con los derechos y libertades del hombre, ya aceptados. Este organismo afirmó los nuevos derechos, entre los que necesariamente se incluyen el derecho a la paz, el derecho al desarrollo que garantice un mínimo de condiciones de vida digna para todos los pueblos como objetivo inmediato, el derecho a gozar de un ambiente sano, adecuado y ecológicamente equilibrado, y el derecho a beneficiarse del patrimonio común de la humanidad, todos interdependientes con todos los demás derechos y libertades de la persona humana, constituyendo una unidad indivisible.

2.1 Reconocimiento del derecho a un ambiente sano y ecológicamente equilibrado en las convenciones e instrumentos internacionales

Este derecho en particular es de amplia extensión, constituyendo el principio de corresponsabilidad Estado-individuo una de las bases para su protección. Dentro del derecho a un ambiente sano, se encuentran contenidos principios tales como el de protección de la flora y la fauna, la necesidad del desarrollo sostenible, entre otros.

Comenzaremos diciendo que incluso entre los muchos autores consultados décadas atrás no parecía mayoritaria la opinión de que nos halláramos ante un verdadero derecho humano, tan es así que dentro de los que defendían un criterio positivo, las diferencias a la hora de la definición del concepto son importantes. Esto hace suponer que el debate de reflexión teórica $\mathrm{y}$ el reconocimiento formal en convenios internacionales y en los ordenamientos internos han tenido que recorrer un largo y complicado sendero hasta la actualidad.

Al parecer resultó difícil el intento tan solo de convencer de que el derecho a un ambiente sano es un derecho humano e incluso un derecho fundamental. En realidad, muchos estudiosos del tema coinciden en afirmar que el asunto es complicado por partida doble, dado

3 Gros Espiell Héctor, Los derechos económicos, sociales y culturales en el Sistema Interamericano. Disponible en Internet: http//www. dialnet.unirioja.es/Servet/articulo? código 
que nos enfrentamos a dos conceptos - derechos humanos y ambiente- cuyas definiciones distan mucho de ser precisas.

A partir de las últimas décadas, sin embargo se ha asumido su existencia sin ningún tipo de pretensión, obviando incluso su previa conceptualización, y lo prueba el texto de la Declaración Universal de Derechos Humanos de 1948 y del estudio de las Constituciones aprobadas en los últimos años del siglo pasado.

En la Declaración de las Naciones Unidas de 1948, sin ser este un documento referido directamente al ambiente, encontramos los principios sobre los que se podría asentar el derecho a un ambiente adecuado, en tanto uno de sus artículos expresa que "toda persona tiene el derecho a un nivel de vida adecuado que le asegure, así como a su familia, la salud y el bienestar...". ${ }^{4}$ Posteriormente, en el Pacto Internacional de Derechos Económicos, Sociales y Culturales de 1966 se hace ya referencia directa a la necesidad de mejorar el ambiente como uno de los requisitos para el adecuado desarrollo de la persona.

Con anterioridad a este pacto, se había firmado en Roma la Convención Europea de Protección de los Derechos del Hombre y de las Libertades Fundamentales, el que mencionamos por ser un instrumento por el que se crearon tanto la Comisión Europea de Derechos del Hombre como el Tribunal Europeo de Derechos del Hombre, instancias ante las cuales, si bien no se puede alegar directamente el derecho a un ambiente sano y ecológicamente equilibrado, este ha obtenido su protección al ser conectado con la defensa de otros derechos ejercitables directamente, como es el caso del derecho a la vida y salud, como veremos más adelante.

La conocida Declaración de las Naciones Unidas sobre Medio Ambiente Humano (Estocolmo, 1972) establece ya un derecho del hombre a "condiciones de vida satisfactorias en un ambiente cuya calidad le permita vivir con dignidad y bienestar". Como contrapartida a este derecho, se establece el "deber solemne de proteger y mejorar el medio ambiente para las generaciones presentes y futuras". 5

En la Reunión Mundial de Asociaciones de Derecho Ambiental celebrada en Limoges entre el 13 y el 15 de noviembre de 1990, se aprobó una declaración que recomienda que el derecho del hombre al ambiente sano debe ser reconocido a nivel nacional e internacional de una manera explícita y clara, y que los Estados tienen el deber de garantizarlo.

En la Cumbre de Río de Janeiro de 1992, quedó patente el poder de convocatoria de la

Ver Artículo 25 de la Declaración Universal de los Derechos Humanos.

Principio 2. Conferencia de las Naciones Unidas sobre el Medio Humano. Estocolmo, 16 de junio de 1972. 
cuestión ambiental, al estar representados 170 países y asistir más de 100 jefes de Estado. En esta cumbre se consolidó la evolución del reconocimiento al derecho a un ambiente sano y ecológicamente equilibrado al señalar en su Principio Primero que todos los seres humanos tienen derecho a una vida saludable y productiva en armonía con la naturaleza.

En este orden de ideas, el paso más significativo ha sido la consolidación en la década de los noventa de la tendencia a elevar los principios ambientales a rango constitucional, ${ }^{6}$ reconociéndose doctrinalmente a partir de ese momento de forma inobjetable que el derecho a un ambiente sano y ecológicamente equilibrado es un derecho fundamental del ser humano, criterio que ha tenido resonancia a partir de su inclusión como tal en varios textos constitucionales.

\subsection{Dimensión conceptual del derecho a un ambiente sano y ecológicamente equilibrado}

El concepto de dimensión se refiere a la perspectiva desde la cual se analiza un determinado proceso en circunstancias específicas, y en consecuencia, los aspectos que dimensionan un derecho integran generalmente su contenido esencial, siendo este último "la parte del contenido de un derecho sin la cual este pierde su peculiaridad, o dicho de otro modo, lo que hace que sea reconocible como derecho perteneciente a un determinado tipo"?

En el caso que nos ocupa, las dimensiones que acompañan el contenido esencial del derecho a un ambiente sano y ecológicamente equilibrado evidentemente se inspiran en el principio primero de la declaración formulada como resultado de la Conferencia de las Naciones Unidas sobre el Medio Humano, reunida en Estocolmo del 5 al 16 de junio de 1972, la cual proclama que "el hombre tiene el derecho fundamental a la libertad, la igualdad y el disfrute de condiciones de vida adecuadas en un medio de calidad tal que le permita llevar una vida digna y gozar de bienestar, y tiene la solemne obligación de proteger y mejorar el medio para las generaciones presentes y futuras" (...)”. ${ }^{8}$

$\mathrm{Al}$ parecer siguiendo esta misma lógica de pensamiento a la hora de abordar la esencia o el contenido básico de este derecho, los autores consultados lo identifican partiendo de una doble dimensión, implícita en su esencia: la primera relativa al derecho a preservar la vida individual en un entorno adecuado, y la segunda en cuanto derecho de la especie a subsistir en las generaciones futuras en un entorno adecuado.?

6 Borrero, José María. "Promesas y límites del Derecho Ambiental”, disponible en internet en: www.ine.gob.mx/ueajei/publicaciones/libros/363/cap18.html

Asensi Sabater, José, Constitucionalismo y Derecho Constitucional. Materiales para una introducción, Tirant Lo Blanch, Valencia, 1996, p. 235.

8 Declaración de Estocolmo sobre Medio ambiente. 16 de junio de 1972.

9 Ídem. 
Coincidimos plenamente en que ambas dimensiones acompañan el contenido esencial del derecho, pues racionalmente el derecho a un ambiente sano y ecológicamente equilibrado implica tanto la preservación del derecho a la vida como el de garantizar este derecho a las futuras generaciones, puesto que en cuanto a acción colectiva de derecho podemos identificar si se quiere una subdimensión ética de solidaridad, ya que las futuras generaciones dependen de nuestro legado ambiental, de tal suerte que aquellos que todavía no pueden ser titulares de derechos podrán serlo cuando nazcan, en la medida en que la acción colectiva protectora del ambiente lo garantice.

En este caso, el concepto de ambiente sano, uno de los elementos claves dentro de la referida primera dimensión de este derecho, no solamente tiene que ver con la preservación y no contaminación de los elementos y recursos naturales, sino además con todos aquellos ámbitos donde el hombre irrumpe con su actividad constructora. Cuando hablamos de un ambiente sano, nos referimos a significa una ciudad con alcantarillado, con agua corriente, con control de ruidos molestos y de emanaciones, y con espacios verdes capaces de contener el desproporcionado y poco planificado avance urbano. ${ }^{10}$

En cuanto a ambiente equilibrado, el otro elemento clave implícito en la segunda dimensión del derecho a un ambiente sano y ecológicamente equilibrado, para nosotros significa adecuación y sostenibilidad, puesto que existe una debida correspondencia de las partes respecto de un todo que debe ser homogéneo y armónico. No es una noción que se refiere a los equilibrios naturales del ambiente intangible, aquel donde el hombre no ha tenido actividad alguna, significa el equilibrio de los ambientes transformados por el hombre, lo que quiere decir que a las modificaciones a que se somete ese ambiente se le deben buscar respuestas que sean equivalentes, en condiciones aceptables, a las que resultan de la propia actividad del hombre. ${ }^{11}$

Podemos agregar a todo lo dicho que dentro del contenido esencial del derecho, el concepto de ambiente sano tiene un contenido amplio que equivale a la aspiración a mejorar el entorno de vida del ser humano, de manera que desborda los criterios de conservación natural para ubicarse dentro de la esfera que desarrolle la persona, sea familiar, laboral o la del medio en cual habita. En su segunda dimensión, es decir, visto como el derecho a un ambiente ecológicamente equilibrado, este derecho posee un contenido más restringido, referido a una parte importante del entorno en el que se desarrolla el ser humano, al equilibrio que debe existir entre el avance de la sociedad y la conservación de los recursos naturales. ${ }^{12}$

10 Juan Leyva, "Derecho ambiental y derechos individuales, tratamiento del tema en la Reforma Constitucional de 1994”, Argentina, P.1 Universidad Nacional de Lomas de Zamora.

11 Ídem.

12 Sentencia No. 00644 de 1999. Sala de lo Constitucional de la Corte Suprema de Justica. Costa Rica. Disponible en internet: http//www.uc3m.es/uc3m/inst/MGP/PCI9MAM.pdf 


\subsection{Clasificación y naturaleza del derecho a un ambiente sano y ecológicamente equilibrado}

El derecho a un ambiente sano y ecológicamente equilibrado podemos ubicarlo conceptualmente atendiendo al sujeto dentro de los derechos colectivos. Así, por su contenido, conforme a la clasificación de P. Pérez Tremps, es de ámbito personal; por su naturaleza, en cambio, clasifica dentro de los derechos de libertad. ${ }^{13}$ Por sus garantías debería, según nuestro entender, estar ubicado, por su importancia, dentro de los derechos con garantías reforzadas.

En cuanto a la naturaleza jurídica, la doctrina se muestra aún contradictoria, pues si bien para algunos tratadistas participa del carácter de los derechos subjetivos, para otros, al no poder enmarcarse exactamente dentro de los presupuestos de estos, debería ubicarse dentro de los derechos de la personalidad. ${ }^{14}$

La vinculación del derecho a un ambiente sano con otros derechos humanos de su misma generación y de otras lo hace un derecho sui generis, más aún cuando se analiza su naturaleza jurídica, ya que algunos tratadistas, como ya expresamos, lo consideran un derecho de la personalidad, debido a que la finalidad o intención de satisfacer las necesidades de tutela que presentan determinadas situaciones, de gran importancia y que afectan directamente a la persona, provoca cierta sensibilidad jurídica, siendo por tanto parte de la vida en sociedad y mutable según el momento histórico de referencia.

Otra situación que afecta la naturaleza de este derecho y que lo distingue de los ubicados en las anteriores generaciones se pone de manifiesto cuando se trata de determinar al sujeto titular de los derechos colectivos, pues estamos en presencia de una diversidad de personas y un hecho cuyo objeto no está bien definido.

13 En este sentido, sin embargo, muchos consideran que la frontera entre los derechos de libertad y los derechos de prestación a veces se difumina, ya que casi todos los derechos requieren algún tipo de actividad del Estado que los haga accesibles a los ciudadanos. En el caso específico del derecho a un ambiente sano y ecológicamente equilibrado, en cuanto al criterio de intervención estatal o no para la concreción de su efectividad, digamos que existen divergencias doctrinales en esta problemática. En tanto algunos consideran que el derecho a un ambiente sano, a diferencia de los derechos de segunda generación, llamados de prestación, en los que la intervención de los poderes públicos resulta requisito para su propia existencia, en el caso del derecho a un ambiente sano no se exige este. Por ejemplo, en el caso de una acción previsora de los efectos sobre la biosfera, puesto que ha sido la naturaleza la que ha provisto los parámetros de la biosfera, la participación del Estado queda limitada a la protección de lo preexistente. Análoga situación se da con el derecho a la vida, que el Estado no provee sino que únicamente protege. Según estos últimos razonamientos, el derecho a un ambiente sano en relación con la actividad del Estado guarda grandes analogías con los derechos civiles y políticos - derechos de primera generación-, ya que el Estado debe reconocerlos y simplemente tutelar que no sean violados, sin que su actuación positiva sea imprescindible.

14 Como se conoce, el origen de los derechos de la personalidad no fue otro que el fin o la intención de satisfacer las necesidades de tutela que presentan determinadas situaciones de gran relevancia, por afectar directamente a la persona, $y$ que, por lo tanto, provocan un movimiento de sensibilidad jurídica, y son, por la misma esencia de la vida en sociedad, mutables según el momento histórico al que se haga referencia. Es el caso del derecho a la intimidad, a la propia imagen, etc. 
En relación con esta problemática, inicialmente la doctrina italiana pero también la de otros países, concretamente la española, han acuñado la noción de intereses difusos, que como han expresado estudiosos del tema no constituye un concepto acabado y categorial sino más bien invoca una idea-fuerza renovadora de la clásica e insuficiente tutela procesal. ${ }^{15}$

Este tipo de problemas afectan a una generalidad, la cual tiene un interés por solucionar dicho asunto, teniendo que satisfacerse la necesidad (o interés) del grupo humano para satisfacer el de cada uno. Este es el ejemplo de derechos subjetivos colectivos, pero cuando el grupo humano es indeterminado, es decir, no tiene límites precisos en referencia a las personas, se está frente a un interés difuso.

Podemos decir que los intereses difusos se caracterizan por:
a) Ser transindividuales.
b) Ser indivisibles.
c) Presentar titulares indeterminados.
d) Estar ligadas las personas por circunstancias de hecho.

Lo anterior implica que la satisfacción del interés de uno de los miembros de esa comunidad es la de todos, y el perjuicio o lesión de uno va en detrimento de la generalidad.

En términos doctrinarios también existen valiosos aportes, entre los que se halla el de Osvaldo Alfredo Gozaíni, quien sostiene que "el desarrollo mismo de la sociedad ha ido determinando una superación de los derechos individuales hacia la socialización de los mismos, mirando el interés del conjunto antes que el de los particulares". Este autor da su interpretación sobre por qué se les denomina derechos difusos, explicando sencillamente que es porque los principales obstáculos a superar eran en primer término la teoría procesal de la legitimación, al no encontrarse el derecho subjetivo individual; en segundo lugar, por el objeto tutelado, al no ser específico; y por último, por la protección jurídica, por los efectos posibles que alteraban instituciones consagradas por la seguridad jurídica como "cosa juzgada". ${ }^{16}$

El derecho a un ambiente sano y ecológicamente equilibrado también es considerado por la doctrina como un derecho continente, es decir, que contiene otros derechos, y su característica especial es integrar los derechos de la persona en su dimensión vital, con la

15 Contreras Nieto Miguel Ángel, Los derechos difusos, México, Comisión de Derechos Humanos de México, 2001, p.13.

16 GOZAÍNI, Osvaldo Alfredo... "Procesos colectivos: la tutela de los derechos difusos", disponible en internet: htpp//www: CLK?IKT $=1016 \&$ TRM 
característica especial de que no solo se desarrolla en la viabilidad biológica del ser humano, sino que integra la relación con su entorno, y que además no solo se restringe al titular individual y actual del derecho, sino que la titularidad de este derecho se proyecta en las generaciones futuras. ${ }^{17}$

\subsection{Relación con otros derechos}

Es evidente la existencia de una estrecha relación entre la situación ambiental y el goce efectivo de los derechos humanos, en especial del derecho a la salud, que además de ser un derecho en sí mismo, es condición indispensable para el ejercicio de los demás derechos. Sabemos que esta relación no se concreta solo en el reconocimiento de la existencia del derecho a vivir en un ambiente sano, sino en la obligación inexcusable del Estado de dirigir el proceso de desarrollo en un marco de derechos humanos, es decir, respetándolos y garantizándolos a través de las políticas públicas.

Se ha demostrado el estrecho vínculo entre el equilibrio ecológico y el goce de los derechos humanos, puesto que las alteraciones a los ecosistemas pueden generar afectaciones severas a la vida, integridad, salud, e incluso la paz y seguridad de las personas. Asimismo, la gestión no sostenible de recursos naturales y la vulneración de derechos pueden generar escenarios de gran tensión social y conflictos violentos, a lo que se suma la deslegitimación de la autoridad, que también afecta a la cultura política del país. Al respecto, el Consejo de Seguridad de las Naciones Unidas, por ejemplo, ha declarado que existen causas no militares que ponen en riesgo la paz y seguridad internacional, entre las cuales se encuentran las ecológicas. ${ }^{18}$

No es extraño, entonces, que en el plano internacional la protección al ambiente se haya concretado a través de la exigencia de respeto a derechos humanos, como los referidos a la vida y la salud.

En tal sentido, podemos decir que un ambiente degradado afectará el goce de otros derechos. De este modo, los derechos a la vida, a la salud, a la información, a la participación, a los derechos culturales, y a tantos otros, se ven comprometidos o vulnerados ante situaciones de degradación ambiental, ya que la falta de implementación de políticas integrales por parte de la administración estatal provoca en el ambiente alteraciones que influyen en la salud, en las oportunidades de trabajo, en la educación y en el acceso a recursos financieros y naturales, alteraciones que a nivel mundial solo han generado pobreza, y la pobreza a su vez repercute en la formación cultural así como en las posibilidades reales de acceder a la educación y a la información necesaria que estimule la participación.

17 Jesús Rafael Vallenas Gaona, “El derecho a un ambiente sano y ecológicamente equilibrado”.

18 Declaración del 31 de enero de 1992, hecha pública con motivo de la reunión de los miembros del Consejo de Seguridad de nivel de Jefes de Estado. 
En cuanto a la vinculación salud-ambiente como parte fundamental de los derechos humanos, lo que aparenta constituir una fórmula simple es en realidad de difícil concreción en la práctica. $Y$ a la vez, sus dos componentes son presupuesto indispensables para el ejercicio de otros derechos, ya que las condiciones de salud-ambiente en que vivan las personas condicionan, en su momento, el grado real de libertad de que disponen para luchar por una vida digna, para acceder al derecho a disfrutar de todo un espectro de bienes y servicios necesarios que, a manera de círculo virtuoso, faciliten el más alto nivel posible de salud física y mental. La plena realización de esta fórmula salud-ambiente como sistema de protección de una sociedad por medio de adecuadas políticas estatales impediría todo tipo de discriminación.

Por último, coincidimos con varios autores que plantean que existe una estrecha vinculación entre el ejercicio del derecho a un ambiente sano y ecológicamente equilibrado y el derecho a la participación y a la información.

En el primero de ellos se ha demostrado que la participación de organizaciones sociales, redes especializadas, centros laborales, estudiantiles y la comunidad es decisiva para difundir y fomentar el conocimiento sobre temas ambientales y el derecho de estos sobre el mismo, así como incidir en el diseño institucional de políticas públicas que prioricen un ambiente sano y un plan de acción para mejorar la salud ambiental de la comunidad.

Por otro lado, el derecho al ambiente implica también el derecho a acceder a la información necesaria para protegerlo y protegerse contra riesgos ambientales, pues, como se sabe, la sola consagración de derechos no es garantía de su ejercicio, si los ciudadanos no están informados acerca de sus derechos y las instituciones que las tutelan no son capaces de hacerlos cumplir. Las nuevas herramientas legales que las distintas constituciones consagran deben ser difundidas e incorporadas por la ciudadanía a sus prácticas cotidianas. Como sostiene Bobbio, el problema de los derechos fundamentales ya no consiste en su reconocimiento solemne sino en la posibilidad de tornarlos realmente efectivos.

El acceso a la información sobre el medio ambiente constituye un instrumento necesario para la toma de decisiones, la formulación de políticas y el desarrollo normativo, así como para la planificación y el ordenamiento ambiental del territorio; en otras palabras, la información facilita que el ejercicio de las funciones en cabeza del Estado, el Legislador y la Justicia se haga con los conocimientos necesarios para tal fin.

Por su parte, la información suministrada al ciudadano común o en su poder le permitirá ejercer el adecuado control sobre el ejercicio de las funciones públicas en relación con la protección del medio ambiente o colaborar en ellas, participar en igualdad de condiciones en los procesos de decisiones y, en general, hacer valer sus derechos. 


\subsection{Derecho a un ambiente sano y ecológicamente equilibrado en el Derecho Constitucional Comparado}

Con la finalidad de determinar los elementos comunes y tendencias dominantes en el ámbito internacional, tanto en doctrina como jurisprudencia en relación al reconocimiento constitucional del derecho a un ambiente sano y ecológicamente equilibrado, hemos seleccionado varios países, todos dentro del sistema romano francés; de ellos, tres del continente europeo: Italia en representación de los países cuyos textos constitucionales son anteriores a la década de los sesenta -que como bien se ha dicho son los años que marcan el despegue de la conciencia ambientalista-, y Portugal y España por ser cartas magnas promulgadas en pleno auge de las tendencias constitucionalizadoras de dicho derecho. En el caso de los países latinoamericanos, se los ha elegido por las razones obvias de pertenecer a un mismo contexto geográfico y cultural, con muchas más coincidencias que desencuentros en el tema que nos ocupa.

Podemos comenzar diciendo que muchos Estados, de una manera u otra, reconocen el derecho a un ambiente sano y ecológicamente equilibrado como un derecho fundamental, si bien este reconocimiento no siempre encuentra formulación expresa. Por estas razones, en algunas ocasiones este derecho viene de la mano o conectado con algún otro derecho ya consagrado formalmente. Esto ocurre fundamentalmente con las Constituciones que llevan mayor tiempo de promulgadas.

Es el caso, por ejemplo, de la Constitución italiana, que, promulgada en 1948, no recoge ningún artículo donde se haga referencia expresa al derecho a un ambiente sano. Sin embargo, este derecho ha sido reconocido por vía jurisprudencial al relacionarlo con los artículos 9, 32 y 41 de dicho texto constitucional, referidos respectivamente a la protección del patrimonio histórico y artístico de la nación, a la protección de la salud y a la iniciativa económica.

En este caso, la doctrina italiana, además de relacionar el ambiente con el derecho a la salud, lo califica de paso como derecho fundamental de la personalidad. ${ }^{19} \mathrm{Al}$ respecto, Martín Mateo opina que estas construcciones resultan un tanto forzadas y que, en todo caso, requieren apoyatura adicional en normas ordinarias para permitir el acceso a las instancias jurisdiccionales. ${ }^{20}$

Pudiéramos también referirnos a la Constitución alemana, conocida como Ley Básica de Alemania, que data del año 1948. Esta tampoco reconoce directamente el derecho a un ambiente sano y ecológicamente equilibrado, y no fue sino hasta el año1994 que, mediante

\footnotetext{
Martín Mateo Ramón, Tratado de Derecho Ambiental, Madrid, Editorial Trívium, 1991, p.147.

Ídem.
} 
una enmienda constitucional basada en la jurisprudencia, se estableció el deber del Estado de proteger las condiciones naturales indispensables para la vida como parte de su responsabilidad con las generaciones futuras. A partir de ese momento se realiza un reconocimiento explícito del derecho al ambiente, claro está conectándolo con el derecho a la vida, pues en su artículo 20, que refrenda la protección de las bases naturales de la vida, establece:

Art. $20^{\circ}$. (Protección de las bases naturales de la vida) "Consciente de la responsabilidad hacia las generaciones futuras, el Estado protegerá las bases naturales de la vida mediante legislación y en concordancia con la ley y la justicia, por medio de acciones ejecutivas y judiciales, todo dentro del marco del orden constitucional."

En el caso de Portugal, su Constitución de 1976 en el artículo 9 establece el deber del Estado de proteger los derechos fundamentales. De su redacción se desprende que un requisito para la protección de la herencia cultural de los portugueses es la defensa de la naturaleza, el ambiente y la preservación de los recursos naturales. Sin embargo, el reconocimiento expreso a un ambiente "saludable y ecológicamente equilibrado", así como el deber de protegerlo, viene recogido en el artículo 66 del texto constitucional, en este caso dentro del capítulo referido a los derechos fundamentales económicos, sociales y culturales, el que en su apartado primero dice: "Todos tendrán derecho a un ambiente humano de vida, salubre ecológicamente equilibrado y el deber de defenderlo".

Asimismo, la Constitución portuguesa reconoce el derecho de las personas naturales y jurídicas a recibir compensaciones por los daños causados al ambiente, debiéndose entender que esto será así cuando el daño las afecte directamente.

Nos referiremos, por último, a la actual Constitución española, que, al irrumpir de modo relativamente reciente en el contexto europeo, refrenda de manera directa, tal como lo hace la Constitución portuguesa, el derecho del ciudadano español a un ambiente sano, y que, según el criterio de muchos autores, resulta uno de los textos jurídicos más logrados técnicamente en este aspecto.

Veamos de qué modo establece la Constitución española los derechos del ciudadano a un ambiente sano:

El art. $45^{\circ}$ de la Constitución establece:

1. Todos tienen el derecho a disfrutar de un medio ambiente adecuado para el desarrollo de la persona, así como el deber de conservarlo.

2. Los poderes públicos velarán por la utilización racional de todos los recursos naturales, con el fin de proteger y mejorar la calidad de vida y defender y restaurar el medio ambiente, apoyándose en la inexcusable solidaridad colectiva. 
3. Para quienes violen lo dispuesto en el apartado anterior, en los términos que la ley fije, se establecerán sanciones penales o, en su caso, administrativas, así como la obligación de reparar el daño causado.

Debemos decir que la Constitución española no reconoce este derecho como fundamental. Por eso, algunos autores, ante la falta de asidero en el artículo 45 para justificar la existencia de un derecho fundamental al ambiente, han tratado de conectarlo con el derecho constitucional a la salud, relacionándolo a su vez con el derecho a la vida, ${ }^{21}$ argumento ya utilizado por la doctrina en otros casos abordados por nosotros. Sin embargo, este aspecto tiene tanto defensores como detractores.

Pasemos ahora a ver cómo se materializa el reconocimiento del derecho a un ambiente sano y ecológicamente en el contexto del derecho constitucional latinoamericano, donde, como se sabe, muchas de estas constituciones fueron modificadas con posterioridad a 1992, y otras de reciente dación, como es el caso de la Constitución de la República Bolivariana de Venezuela, incluyeron en sus textos las sugerencias realizadas en la Cumbre de Río de 1992.

Un ejemplo relativamente reciente de reconocimiento formal del derecho al ambiente adecuado lo encontramos en la Constitución de Brasil de 1988, en la que varios artículos hacen referencia al derecho a un ambiente sano y ecológicamente equilibrado. El artículo 225 (Título VIII, relativo al orden social), donde se proclama el medio ambiente como derecho perteneciente a las generaciones presentes y futuras, expresa que "todos tienen derecho a un ambiente ecológicamente equilibrado, en cuanto bien común y elemento esencial para una sana calidad de vida, imponiéndose al poder público y a la colectividad el deber de defenderlo y preservarlo para las presentes y futuras generaciones".

En otros apartados vuelve sobre el mismo aspecto, regulando lo siguiente:

1. Para asegurar la efectividad de ese derecho, incumbe al poder público:

I. Preservar y restaurar los procesos ecológicos esenciales y proveer el manejo ecológico de las especies y ecosistemas;

II. Preservar la diversidad y la integridad del patrimonio genético del país y fiscalizar las entidades dedicadas a la investigación y manipulación de material genético;

III. Definir, en todas las unidades de la federación, espacios territoriales y sus componentes a ser especialmente protegidos, siendo la alteración y supresión solamente a través de ley, prohibida cualquier utilización que comprometa la integridad de los atributos que justifiquen su protección.

21 Martín Mateo Ramón, Tratado de Derecho Ambiental, Madrid, Editorial Trívium, 1991, p.151. 
IV. Exigir en forma de ley para la instalación de obra o actividad potencialmente causadora de significativa degradación al medio ambiente, estudio previo de impacto ambiental, el que se dará a publicidad.

V. Controlar la producción, la comercialización y empleo de técnicas, métodos y substancias que comporten riesgo para la vida, la calidad de vida y el medio ambiente.

VI. Promover la educación ambiental en todos los niveles de enseñanza y la concientización pública para la preservación del medio ambiente.

VII. Proteger la fauna y la flora en forma de ley, y limitar las prácticas que coloquen en riesgo su función ecológica, provoquen la extinción de especies o sometan a los animales a crueldades.

2. Aquel que explora recursos minerales queda obligado a recuperar el medio ambiente degradado de acuerdo con la solución técnica exigida por el órgano público competente en forma de ley.

3. Las conductas y actividades lesivas al medio ambiente sujetarán a los infractores, personas físicas o jurídicas a sanciones penales y administrativas, independientemente de la obligación de reparar los daños causados.

4. La floresta amazónica brasilera, la mata atlántica, la sierra del mar, el pantanal de Mato Grosso y la zona costera son patrimonio nacional, y su utilización se dará en forma de ley dentro de condiciones que aseguren la preservación del medio ambiente, inclusive en cuanto al uso de los recursos naturales.

5. Son indisponibles las tierras desocupadas o arrendadas por los Estados, por acciones discriminatorias, necesarias a la protección de los ecosistemas naturales.

6. Las usinas que operen con reactor nuclear deberán tener sus localizaciones definidas en ley federal, sin la cual no podrán ser instaladas.

La Constitución Política de Colombia de 1991 establece los derechos de sus ciudadanos a un ambiente sano en los siguientes artículos:

Art. $79^{\circ}$. Todas las personas tienen el derecho a gozar de un ambiente sano. La ley garantizará la participación de la comunidad en las decisiones que puedan afectarlo.

Igualmente establece que es deber del Estado proteger la diversidad e integridad del ambiente, conservar las áreas de especial importancia ecológica y fomentar la educación para el logro de esos fines. 
En el artículo 80 dice: "El Estado planificará el manejo y aprovechamiento de los recursos naturales, para garantizar su desarrollo sostenible, su conservación, restauración o sustitución".

Además, deberá prevenir y controlar los factores de deterioro ambiental, imponer las sanciones legales y exigir la reparación de los daños causados. Así mismo, cooperará con otras naciones en la protección de los ecosistemas situados en las zonas fronterizas.

El artículo 81 establece lo siguiente: "Queda prohibida la fabricación, importación, posesión y uso de armas químicas, biológicas y nucleares, así como la introducción al territorio nacional de residuos nucleares y desechos tóxicos".

En este mismo artículo se pronuncia en cuanto a que "el Estado regulará el ingreso al país y la salida de él de los recursos genéticos, y su utilización, de acuerdo con el interés nacional."

En el artículo 82 queda establecida la responsabilidad estatal de la manera siguiente: "Es deber del Estado velar por la protección de la integridad del espacio público y por su destinación al uso común, el cual prevalece sobre el interés particular. Las entidades públicas participarán en la plusvalía que genere su acción urbanística y regularán la utilización del suelo y del espacio aéreo urbano en defensa del interés común”.

En el caso de la Constitución Política Mexicana de 1917,22 se hace un reconocimiento implícito al derecho ciudadano:

Artículo $4^{\circ}$. (...) Toda persona tiene derecho a un medio ambiente adecuado para su desarrollo y bienestar.

Artículo 25. (...) Bajo criterios de equidad social y productividad se apoyará e impulsará a las empresas de los sectores social y privado de la economía, sujetándolos a las modalidades que dicte el interés público y al uso, en beneficio general, de los recursos productivos, cuidando su conservación y el medio ambiente. La ley establecerá los mecanismos que faciliten la organización y la expansión de la actividad económica del sector social: de los ejidos, organizaciones de trabajadores, cooperativas, comunidades, empresas que pertenezcan mayoritaria o exclusivamente a los trabajadores y, en general, de todas las formas de organización social para la producción, distribución y consumo de bienes y servicios socialmente necesarios.

La Constitución de la República Bolivariana de Venezuela, resultado del proceso constituyente del año 2000, refrenda de forma directa el derecho a un ambiente sano y ecológicamente equilibrado, dedicando el capítulo IX íntegramente a los derechos ambientales

22 Desde entonces se han realizado numerosas modificaciones a la Constitución Política Mexicana, lo que le ha permitido incluir el derecho a un ambiente sano. 
y proclamando, en el artículo 127, que "es un derecho y un deber de cada generación proteger y mantener el ambiente en beneficio de sí misma y del mundo futuro. Toda persona tiene derecho individual y colectivamente a disfrutar de una vida y de un ambiente seguro, sano y ecológicamente equilibrado. El Estado protegerá el ambiente, la diversidad biológica, genética, los procesos ecológicos, los parques nacionales y monumentos naturales y demás áreas de especial importancia ecológica. El genoma de los seres vivos no podrá ser patentado, y la ley que se refiera a los principios bioéticos regulará la materia”.

El texto constitucional bolivariano igualmente defiende el principio de corresponsabilidad cuando en el propio artículo deja sentado que "es una obligación fundamental del Estado, con la activa participación de la sociedad, garantizar que la población se desenvuelva en un ambiente libre de contaminación, en donde el aire, el agua, los suelos, las costas, el clima, la capa de ozono, las especies vivas, sean especialmente protegidos, de conformidad con la ley".

En el artículo 128, refrenda las dimensiones inherentes a este derecho, pero además vincula conceptos esenciales para su disfrute pleno, como lo son, sin duda, la participación ciudadana y la debida información sobre dichos temas, y en este sentido se pronuncia textualmente en cuanto a que "el Estado desarrollará una política de ordenación del territorio atendiendo a las realidades ecológicas, geográficas, poblacionales, sociales, culturales, económicas, políticas, de acuerdo con las premisas del desarrollo sustentable, que incluya la información, consulta y participación ciudadana. Una ley orgánica desarrollará los principios y criterios para este ordenamiento".

En el caso del Perú, la protección del derecho a un ambiente sano se hace evidente a nivel constitucional desde 1979, cuando se regula por primera vez en el artículo 123 el derecho de todos los peruanos a habitar en un ambiente saludable.

Luego de la Cumbre de Río de Janeiro en 1992, esta protección se amplió estableciéndose en el artículo 2, numeral 22 de la Constitución que "toda persona tiene derecho a la paz, a la tranquilidad, al disfrute del tiempo libre y al descanso, así como a gozar de un ambiente equilibrado y adecuado al desarrollo de su vida".

El mandato general del artículo 2, numeral 22 de la Constitución, es seguido por un capítulo dedicado al ambiente. Los artículos 66 y 67 establecen el dominio del Estado sobre los recursos naturales, así como la forma de acceso de los privados a dichos recursos. Para los constitucionalistas peruanos, la importancia de establecer un orden público ambiental, además de otorgar el acceso a sus recursos naturales en el marco de un uso sostenible de los mismos, es que, según ellos, se reconoce la definición de una materia cuya regulación es de orden público y no privado; por tanto, el Estado debe asumir la responsabilidad de regular, normar, controlar y sancionar este orden público. 
Veamos por último, en el contexto latinoamericano, la Constitución de la nación argentina, ${ }^{23}$ donde el derecho a un ambiente sano se encuentra reconocido en el artículo 41, el mismo que textualmente establece:

"Todos los habitantes gozan del derecho a un ambiente sano, equilibrado, apto para el desarrollo humano y para que las actividades productivas satisfagan las necesidades presentes sin comprometer las de las generaciones futuras; y tienen el deber de preservarlo. El daño ambiental generará prioritariamente la obligación de recomponer, según lo establezca la ley”.

Igualmente define el deber estatal en la tutela ambiental cuando deja establecido que las autoridades proveerán a la protección de este derecho, a la utilización racional de los recursos naturales, a la preservación del patrimonio natural y cultural y de la diversidad biológica, y a la información y educación ambientales.

Además, se pronuncia sobre la responsabilidad de las autoridades nacionales en cuanto a dictar las normas que contengan los presupuestos mínimos de protección, y de las provinciales respecto de dictar las necesarias para complementarlas, sin que aquellas alteren las jurisdicciones locales.

\section{Las garantías del derecho a un ambiente sano y ecológicamente equilibrado}

\subsection{Reflexiones en torno a las garantías de los derechos}

Las garantías a los derechos humanos han sido definidas como el conjunto de instrumentos jurídicos de aseguramiento de los derechos y libertades, y por ende, del valor normativo de la Constitución. ${ }^{24}$

El término garantía se encuentra vinculado en su origen a las primeras declaraciones de derechos en los textos constitucionales, considerándose en esa época que los derechos estaban garantizados con su simple establecimiento o su consagración en la carta fundamental. Incluso se ha considerado que la primera garantía del derecho es su reconocimiento; sin embargo, la sola consagración constitucional de los derechos fundamentales no evita que sus titulares, en ocasión de ejercerlos, pueden apreciarlos disminuidos, amenazados o vulnerados, bien por el Estado o por los particulares; por lo tanto, este reconocimiento debe ir acompañado de garantías que aseguren con eficacia el libre ejercicio de tales derechos.

La doctrina se ha encargado de establecer que derecho y garantía son dos categorías que guardan una estrecha relación, aun cuando sus significados sean diferentes. Así, está reservado

\footnotetext{
Sancionada en 1853, con reformas en 1860, 1866, 1898,1957 y 1994.

24 Gómez Sánchez Yolanda, Derechos y libertades. Introducción al Derecho Político, Madrid, UNED, 1997, p. 186.
} 
a la garantía un lugar de significativa importancia para la estabilidad de los ordenamientos jurídicos en cuanto a los derechos que estos pregonan, al punto que se ha dicho con razón que los derechos valen lo que valen sus garantías.

De esta forma, las garantías de los derechos humanos pasan a convertirse en el complemento imprescindible para hacer posible el tránsito que media desde el reconocimiento de los derechos hasta su real eficacia jurídica en las relaciones humanas. Es decir, la efectividad de los derechos depende tanto de su reconocimiento constitucional como de la existencia de mecanismos adecuados, prácticos y expeditos para prevenir sus violaciones y reaccionar contra ellas, junto a la necesaria condicionalidad material para su pleno disfrute.

Numerosas han sido las vías implementadas por la doctrina dirigidas a garantizar que los ciudadanos disfruten de manera real y efectiva de sus derechos constitucionalmente reconocidos. Así, hoy por ejemplo se acepta que los derechos fundamentales tienen eficacia directa, esto es, que vinculan a los poderes públicos y son inmediatamente tutelables por los tribunales sin necesidad de leyes interpuestas. La regulación de los derechos y libertades incluye mandatos al legislador, garantías judiciales, etc.

Debido a lo anterior, también han sido diversas las clasificaciones señaladas por la doctrina para enmarcar los mecanismos de protección empleados por los diferentes sistemas de Derecho. En este sentido, seguimos la clasificación propuesta por la profesora Danelia Cutie Mustelier, compartida también por tratadistas de reconocido prestigio como Fix-Zamudio. Estos distinguen tres tipos esenciales de garantías: las jurisdiccionales, las no jurisdiccionales y las normativas o abstractas. Veamos brevemente cada una de ellas.

Las garantías jurisdiccionales son aquellas que dan la posibilidad de demandar ante órganos de este género (tribunales) la preservación o el restablecimiento de los derechos humanos. Se les conoce con el nombre de instrumentos reactivos o garantías concretas, pues se ofrecen a los ciudadanos para que, en el caso concreto de que se produzca la vulneración de un derecho, puedan acudir a ellas y obtener la debida protección

Dentro de las garantías jurisdiccionales cabe destacar:

a) Garantias jurisdiccionales generales u ordinarias, que Fix-Zamudio denominó remedios procesales indirectos, refiriéndose a los procedimientos ordinarios (civil, penal, laboral y la justicia administrativa) a través de los cuales se protegen los derechos de carácter ordinario, pero que en forma refleja pueden utilizarse para la tutela de los derechos humanos.

b) Garantías jurisdiccionales especificas, que son los remedios procesales creados exclusivamente para el muy específico fin de proteger los derechos humanos; son, por tanto, procesos de cognición limitada. Se distinguen por brindar de forma directa, rápida y eficaz 
tutela a los derechos humanos reconocidos por el ordenamiento constitucional. Esto significa que el modo de proceder debe caracterizarse por la inmediatez, por la máxima urgencia y abreviación en la tramitación y solución, compatibles con un conocimiento adecuado del problema a dilucidar. Además, los efectos del fallo protector deben ser esencialmente reparadores, es decir, no solo se requiere que el fallo imponga sanción sino que además disponga la restitución del goce de sus derechos al afectado.

c) Ordinarias, aplicables cuando se trata de un procedimiento específico para la defensa de los derechos humanos ante los propios órganos judiciales ordinarios. Ejemplo: el hábeas corpus.

d) Extraordinarias, aplicables cuando se trata de un procedimiento específico para la defensa de los derechos humanos ante órganos jurisdiccionales especiales o especializados, como es el caso de los recursos o procedimientos establecidos en algunos países ante los Tribunales Constitucionales.

Un segundo escalón dentro de la diversidad de mecanismos de protección de los derechos humanos lo constituyen las garantias no jurisdiccionales, que no pueden considerarse como instrumentos procesales en sentido estricto, pues se trata de órganos o instituciones que se han establecido con la función esencial de tutelar o fiscalizar los derechos humanos. En este caso se encuentra el Ombudsman, de origen escandinavo y que ha sido asimilado por varios ordenamientos contemporáneos dentro de los que ha recibido distintas denominaciones, como la de defensor del pueblo, en el caso de España y Venezuela. Aunque ha ido evolucionando, la misión fundamental de esta institución ha sido la de supervisar la actividad de los funcionarios públicos para defender a los particulares contra el proceder ilegal de la administración pública.

También se sitúa dentro de estas garantías al Ministerio Fiscal, que tiene atribuida la función de ejercitar la acción penal en representación del Estado. Es un órgano de control y fiscalización de la legalidad, y en tal sentido, puede promover la acción de la justicia en defensa de los derechos de los ciudadanos. Es evidente que esta institución carece de naturaleza procesal, y aunque posee sus propias peculiaridades que la distinguen del Ombudsman, en materia de protección de los derechos humanos tiene funciones similares en cuanto a la recepción, atención, tramitación, investigación y solución de las quejas planteadas por la población. Sus decisiones carecen de fuerza vinculante y adoptan la forma de proposiciones, recomendaciones o sugerencias.

El tercer grupo de mecanismos protectores de los derechos humanos lo conforman las llamadas garantías normativas o abstractas, cuyo objeto es evitar que la actividad de los órganos estatales, fundamentalmente el Legislativo y el Ejecutivo, pueda implicar un desconocimiento o vulneración de los derechos humanos. En este grupo encontramos la reserva de ley, el 
contenido esencial de los derechos, los límites intrinsecos en la regulación constitucional y la eficacia directa.

\subsection{Tutela del derecho a un ambiente sano y ecológicamente equilibrado}

Del estudio realizado sobre la naturaleza y esencia del derecho a un ambiente sano y ecológicamente equilibrado creemos que ha quedado suficientemente demostrado el hecho de que nos encontramos frente un derecho con características especiales que lo distinguen del resto de las anteriores generaciones de derechos, e incluso presenta significativa connotación aun dentro de aquellos derechos que clasifican dentro de los llamados de solidaridad o de la tercera generación. Por tanto, coincidimos plenamente con un gran número de autores que proclaman la necesidad de implementar garantías especiales para un derecho que de alguna forma también lo es, sobre todo por la esencia del derecho tutelado, con implicaciones no solo para la vida y supervivencia de su titular supuestamente afectado, sino para la supervivencia de las futuras generaciones, e incluso -lo que resulta más dramático aún- para la supervivencia de todo el planeta con sus numerosas formas de vida.

En este sentido, hemos podido advertir que, con las diferencias propias que corresponden a cada país, todas las normativas nacionales sobre ambiente contienen una serie de medidas administrativas generales que especifican los órganos estatales o locales encargados de su aplicación y control además de regular el procedimiento en la obtención de licencias para desarrollar actividades contaminantes controladas. Otras establecen procedimientos de revisión de resoluciones administrativas para la obtención de licencias y para la comprobación de actividades, y en muchas ocasiones insertan un procedimiento sancionador para los casos de incumplimiento. Sin embargo, brillan por su ausencia mecanismos eficaces para el acceso del ciudadano a la tutela judicial efectiva cuando le ha sido violado el derecho a un ambiente sano y ecológicamente equilibrado. En tal caso ocurre que los sujetos se ven obligados a aprovechar las vías procesales ordinarias y tratan de hacer valer en ellas sus pretensiones ambientales; sin embargo, estas, por las razones ya señaladas y otras que explicaremos a lo largo del trabajo, no alcanzan el nivel de efectividad adecuado o requerido.

Dicho de otro modo, se trata de que el nivel de consenso alcanzado en el reconocimiento del derecho a un ambiente sano por casi todos no ha ido acompañado de igual modo en la implementación de los mecanismos para su efectiva garantía, entendidas las garantías como las vías procesales para lograr una tutela judicial efectiva ${ }^{25}$ por parte del ciudadano, y sin las

25 La tutela judicial efectiva de los derechos fundamentales constituye un rasgo común al constitucionalismo contemporáneo, cual expresión de la seguridad jurídica que debe ofrecerse a sus titulares en el disfrute de los mismos. Su establecimiento implica el derecho a acceder a los tribunales o jueces, sometidos exclusivamente en su actividad fundamental de impartir justicia al imperium del Derecho; a obtener de estos un fallo justo y, posteriormente, la ejecución del mismo. En sentido general, sobre la tutela judicial efectiva vid.: Asensi Sabater, op. cit., pp. 122; Pérez Royo, Curso..., op. cit., pp. 311. 
que definitivamente no existirá el disfrute efectivo del derecho, aunque se haga formalmente su reconocimiento por todos.

Como hemos reiterado, el tema de las garantías al derecho a un ambiente sano se complica un tanto partiendo de la singularidad del mismo, que lo distingue de los restantes. En efecto este derecho precisa de determinados presupuestos en el orden procesal para que sea realmente efectiva su tutela en caso de vulneración; y es que según nuestra consideración, desde la perspectiva del Derecho Comparado no existe una solución homogénea al respecto, aunque sí diferentes vías a través de las cuales se logra o pretende lograr el acceso a la tutela efectiva del ciudadano, esencialmente a partir del acomodo de las instituciones tradicionales del Derecho, que, como se verá, están lejos de ofrecer la protección adecuada, y que incluso, las más de las veces, resultan inaccesibles o desconocidas para los ciudadanos.

Como se ha sostenido, una cuestión elemental es que las nuevas herramientas legales que las distintas constituciones consagran deben ser difundidas e incorporadas por la ciudadanía a sus prácticas cotidianas. Como sostiene Bobbio, el problema de los derechos fundamentales ya no consiste en su reconocimiento solemne sino en la posibilidad de tornarlos realmente efectivos. ${ }^{26}$

Por lo tanto, el reconocimiento del derecho a un ambiente sano y equilibrado y el desarrollo de la legislación de protección del ambiente requieren de medios o instrumentos a través de los cuales se asegure el efectivo cumplimiento de esas normas por parte del Estado y de los particulares.

De esta manera, la persona perjudicada puede reclamar o demandar la defensa o conservación de su derecho ante el Poder Ejecutivo (por la vía administrativa), y/o ante el Poder Judicial (por la vía jurisdiccional).

Este asunto de las garantías cobra importancia a partir de que el acceso a la justicia en defensa de un ambiente sano es una de las formas a través de las cuales los ciudadanos decididamente participan en el control del cumplimiento de las normas ambientales.

\subsection{Tutela del derecho a un ambiente sano y ecológicamente equilibrado en el Derecho Comparado}

Con el empleo de los mismos criterios de comparación empleados en el caso del reconocimiento de este derecho, refirámonos a continuación a algunas de las vías empleadas en el Derecho Comparado para la defensa del derecho a un ambiente sano y ecológicamente equilibrado.

26 Beatriz Kohen, "El control ciudadano del derecho a un medio ambiente sano en la ciudad de Buenos Aires". 
Encontramos el caso de España, cuyo sistema jurídico, entre los sistemas europeos, de manera directa reconoce constitucionalmente el derecho a un ambiente sano y ecológicamente equilibrado. No obstante, al realizar un análisis detenido de la norma y del apartado constitucional en el que se encuadra el artículo 45, podemos darnos cuenta de que el mismo tiene un alcance programático, no siendo posible imponer efectividad práctica de su mandato en tanto el legislador ordinario no ha precisado y matizado su alcance. ${ }^{27}$

Como el resto de los ordenamientos jurídicos de los países del viejo continente, la Constitución española no dispone de una garantía específica para la defensa del derecho a un ambiente sano y ecológicamente equilibrado. Refiriéndose a este particular, el tratadista español Canosa Usera dice que "en el artículo 45.1 de la constitución española, como sucede en todas las otras constituciones, parece reconocerse un derecho; sin embargo, a pesar de la fórmula, no resulta sencillo hacerlo valer ante los tribunales, y no tanto porque les apliquemos la cautela del artículo 53.3 de la Constitución española, ${ }^{28}$ sino sobre todo porque aspiraciones subjetivas razonablemente pudieran defenderse con la invocación del derecho a no tener el poder de articularse siempre con garantía de éxito en pretensiones procesales debido a su falta de concreción". ${ }^{29}$

No se han producido en el Derecho positivo español innovaciones relevantes actualmente operativas que favorezcan la defensa procesal de los intereses difusos y más concretamente de carácter ambiental, vacío que no se ha cubierto tampoco por vía de construcciones jurisprudenciales.

En este mismo sentido se pronuncian los estudiosos del tema cuando afirman que por más que sea deseable lo contrario, el art. 45.1 de la Constitución no reconoce a los ciudadanos un derecho que puedan hacer valer directamente ante los tribunales. Por lo tanto, esa cualidad solo se atribuye a los derechos y libertades del Capítulo II del mismo título, con la protección reforzada que se dispensa a los de la sección primera y a la objeción de conciencia del art. 30.2 (ver. art. 53, apartados 1 y 2 de la Constitución). ${ }^{30}$

En sentido general, en todos los países europeos la situación es similar al caso español; es decir, no existe un procedimiento específico a partir del cual el ciudadano pueda lograr la tutela judicial efectiva en casos de violación de su derecho a un ambiente sano. La tendencia doctrinal hoy más generalizada en la mayoría de los Estados es que el sistema de recursos

27 Martín Mateo Ramón, Tratado de Derecho Ambiental, Madrid, Editorial Trívium, 1991, p.150.

28 En el artículo 53.3. de la CE se expresa: "El reconocimiento, el respeto y la protección de los principios reconocidos en el Capítulo tercero informarán la legislación positiva, la práctica judicial y la actuación de los poderes públicos. Solo podrán ser alegados ante la Jurisdicción ordinaria de acuerdo con lo que dispongan las leyes que los desarrollen”.

29 Canosa Usera Raúl, La protección constitucional de los derechos subjetivos ambientales, p. 126.

30 Ídem. 
disponibles en cualquier campo de la acción administrativa se puede también utilizar en cuestiones de ambiente. Las diferencias existentes en este punto no son otras que las que se dan entre los distintos derechos administrativos de los Estados. Así, pues, podemos afirmar que el derecho sobre el ambiente en materia doctrinal no ofrece en este punto ninguna particularidad.

En el contexto latinoamericano, comencemos por el caso de la República del Perú, debido a las soluciones novedosas que en materia procesal ambiental propone. El Código del Medio Ambiente del Perú, por ejemplo, establece, en el artículo 3 de su Título Preliminar, que toda persona tiene el derecho a exigir una acción rápida ante la justicia para la defensa de sus derechos ambientales. A continuación, abordaremos las acciones judiciales que se pueden ejercer en el Perú para la defensa de los derechos ciudadanos a un ambiente sano.

La acción de amparo, en cuanto acción de garantía de los derechos constitucionales, es empleada por los ciudadanos que consideran vulnerado o amenazado su derecho a habitar en un ambiente sano y ecológicamente equilibrado. En este sentido, la Constitución peruana establece en su artículo 200, inciso 2, que la acción de amparo procede "contra el hecho u omisión, por parte de cualquier autoridad, funcionario o persona que vulnera o amenaza" cualquier derecho reconocido por la misma, excepto la libertad individual u otro derecho constitucional conexo, que están protegidos por la acción de hábeas corpus.

En la abundante bibliografía consultada sobre el tema, encontramos que la Corte Suprema del Perú en su reiterada jurisprudencia ha resuelto en primer lugar que la acción de amparo es el medio procesal idóneo para la defensa de intereses difusos, como es el ambiente, y en este sentido, cualquier persona puede accionar en defensa del derecho a un ambiente sano, sin la necesidad de agotar las vías previas.

Otra institución empleada por los ciudadanos peruanos es la acción de cumplimiento, también establecida en el artículo 200, inciso 6, de la Constitución, que establece que la acción de cumplimiento "procede contra cualquier autoridad o funcionario renuente a acatar una norma legal o un acto administrativo, sin perjuicio de las responsabilidades de ley". Esta garantía constitucional es una novedad en la Constitución de 1993, y, según pudimos constatar del estudio de algunos materiales, la misma ya ha comenzado a ser utilizada por los ciudadanos cuando consideran que las autoridades y funcionarios no cumplen con aplicar las normas ambientales a pesar de estar obligados a ello. En la actualidad, existe reiterada jurisprudencia que ha resuelto frente a acciones invocadas por ciudadanos en defensa de sus derechos ambientales, compulsando la obligación que tienen los funcionarios públicos de cumplir con la aplicación de las normas sobre la materia.

El artículo 200 de la Constitución, esta vez en su inciso 3, establece también la garantía 
conocida como acción de habeas data, la misma que procede contra el funcionario, autoridad o persona que vulnera o amenaza el derecho "a solicitar sin expresión de causa la información que requiera y a recibirla de cualquier entidad pública, en el plazo legal, con el costo que suponga el pedido". Este es un medio que está siendo utilizado por los ciudadanos cuando las entidades públicas se niegan a brindar información ambiental, cuestión importante para el ejercicio de sus derechos a un ambiente sano, como ya hemos visto.

En el caso de Colombia, la Constitución como principio basa su sistema de garantías a los derechos colectivos, en especial del derecho a gozar de un ambiente sano, en la participación de la comunidad, considerándola como el más importante de los instrumentos para la defensa de este derecho, al menos desde el punto de vista formal.

Del estudio de la legislación jurídico-ambiental colombiana, comenzando por el texto constitucional, se aprecia el interés por dotar a la comunidad de mecanismos idóneos de participación ambiental, clasificados por algunos autores en normativos y legislativos, de gestión y control administrativo y de control judicial. Los normativos, que buscan regular los principios de protección y uso sostenible de los recursos naturales, tienen su desarrollo a través de la iniciativa popular legislativa y normativa, el referendo, la revocatoria del mandato y el voto programático.

Es evidente que este mecanismo de gestión y control administrativo busca involucrar al ciudadano en las decisiones que tomen las autoridades en relación con el ambiente. La participación del ciudadano colombiano en la planeación, evaluación y control administrativo se prevé en una serie de normas constitucionales y legislativas, y todas ellas tienden a darle responsabilidad a la ciudadanía y a las organizaciones de la sociedad civil en el efectivo control de sus derechos. La más característica de ellas es la participación prevista en la Ley 99 de 1993, donde se consagra el derecho de todo ciudadano o entidad pública o privada a participar en las actuaciones administrativas relacionadas con la expedición o modificación de licencias ambientales.

El mecanismo de control judicial tiene que ver con las acciones judiciales de origen constitucional y legal estipuladas para defender los derechos fundamentales y colectivos consagrados en la Constitución. Las acciones de origen constitucional son la acción de tutela, las acciones populares - estas con existencia legal antes de la Constitución de 1991- y las acciones de cumplimiento.

La acción de tutela, de origen constitucional, busca la garantía e inmediata protección de los derechos fundamentales particulares. Su objetivo es buscar la protección de la persona vulnerada o amenazada en sus derechos fundamentales, y el accionante es la persona directamente agraviada por una acción u omisión de las autoridades o particulares con 
funciones públicas; en cuanto al procedimiento, se formula la demanda ante un juez de la república a partir de un procedimiento preferencial, breve y sumario.

A pesar de ser un mecanismo creado para el amparo de los derechos fundamentales particulares, a partir de 1991, la acción de tutela en Colombia, de acuerdo con los autores consultados, al parecer ha abierto un espacio importante para la defensa de los derechos colectivos. ${ }^{31}$

En cuanto a las acciones populares, los autores colombianos consultados sobre el tema que nos ocupa tienen el criterio de que son el mecanismo por excelencia para la protección de los derechos e intereses colectivos, entre ellos "el derecho a un ambiente sano"; y su finalidad es proteger a la comunidad en su conjunto respecto de sus derechos e intereses colectivos. Pueden ser interpuestas por cualquier persona a nombre de su comunidad, y no es necesario demostrar la existencia de un daño o perjuicio. Se persigue con ella que el juez ordene hacer o no hacer algo, o que exija tanto la realización de conductas necesarias para volver las cosas al estado anterior, como el pago de una suma de dinero. ${ }^{32}$

Para garantizar y hacer efectivo el reconocimiento de los derechos colectivos, la nueva Constitución colombiana elevó al rango de norma constitucional las acciones populares en el artículo 88, y dejó en manos del legislador su reglamentación. Las acciones populares aún no han sido reglamentadas, pero algunos autores plantean que las mismas van a permitir a numerosas personas que hayan sufrido o teman sufrir un daño interponer una acción ante la autoridad jurisdiccional, a fin de proteger a la colectividad.

En todo caso, como las acciones populares de origen constitucional aún no han sido reglamentadas, el procedimiento ambiental colombiano tiene por lo pronto que seguir tramitando las acciones populares consagradas en el Código Civil, especialmente la acción popular en favor de los bienes de uso público consagrada en el artículo 2355, o la acción popular de daño contingente prevista en el artículo 2359 del mismo estatuto civil y en otras normas, con el procedimiento señalado en la legislación procedimental civil y con todos los problemas de lentitud que este tipo de procedimientos conlleva.

Otro mecanismo previsto en el derecho colombiano para la garantía al derecho a un ambiente sano y ecológicamente equilibrado es, como en el caso peruano, el de la acción de cumplimiento, consagrada en el artículo 87 de la Constitución como una acción pública y que

31 Macías G. Luis, “Aspectos jurídicos de la participación ciudadana en la gestión ambiental en Colombia”.

Disponible en http://www.cica.es/aliens/gimadus/05/colombia.htm

32 Vanegas Angarita Humber, "Régimen ambiental en Colombia”. Disponible en: http://www.monografias.com/trabajos38/ régimen 
tiene el poder de provocar una sentencia que siempre será favorable a los intereses sociales. La misma tiene por objeto hacer efectivo el cumplimiento de leyes o actos administrativos que tengan relación directa con la protección y defensa del ambiente. La puede interponer cualquier persona natural o jurídica ante la jurisdicción contencioso-administrativa, mediante el trámite de un proceso ejecutivo, en este caso para la ejecución de una conducta que es obligatoria. Sin embargo, en su contra se considera que las acciones de cumplimiento ambiental tienen los problemas inherentes al sistema judicial colombiano, uno de los cuales es la lentitud, especialmente, en la jurisdicción contencioso-administrativa.

En cuanto a México, refrenda el derecho a un ambiente sano en el artículo 4 de su Carta Magna, otorgándole la categoría de garantía constitucional. Sin embargo, lo mezcla con otros aspectos como la declaración de igualdad del hombre y la mujer, la libertad de planificación familiar, el derecho a la vivienda, el apoyo a los menores. A decir del tratadista Cantón Zetina, "este contenido tan diverso lo convierte en una miscelánea de declaraciones, de buenas intenciones y recomendaciones sin la fuerza suficiente para derivar de ahí una efectiva protección" ${ }^{33} \mathrm{Al}$ referirse a las garantías reconocidas en el mencionado artículo 4 de la Constitución, el mismo autor las cataloga de ambiguas al considerar que en estas el derecho al medio ambiente adecuado no sitúa al afectado con alguna calidad que le haga posible acreditar el interés jurídico o el perjuicio directo que le permita actuar judicialmente, y tampoco hace posible determinar la omisión o violación que pudiera hacerse valer como violatoria de la garantía reconocida. ${ }^{34}$ Por ello, ante la carencia de mecanismos de garantías al derecho a un ambiente sano, Cantón Zetina propone en primer término el reconocimiento legal de legitimación de las personas y de las comunidades para hacer valer sus intereses difusos y la creación de una Comisión Nacional de Derechos Ambientales, como una instancia adicional para que todo gobernado y los grupos sociales puedan hacer valer sus derechos ambientales frente a los actos u omisiones provenientes de las autoridades que los afecten.

Algunos tratadistas consultados consideran que en México los problemas para la aplicación efectiva de la ley son de carácter institucional, presupuestal y sobre todo de falta de voluntad política, considerándose que se necesita además seguir avanzando en el perfeccionamiento del marco legal para su defensa, ${ }^{35}$ en tanto el acceso a la justicia es difícil de hacerse efectivo en México, pues "las leyes secundarias establecen solo el esquema de afectación directa, que en la práctica es una limitante en materia de Derecho Ambiental. Resultando que en México una persona puede ampararse solo si son violadas sus garantías individuales, pero en los casos

33 Cantón Zetina Óscar, Los derechos a un ambiente adecuado y la Comisión Nacional de Derechos Ambientales de México, Biblioteca Digital UNAM, p. 170.

34 Ídem., p. 171.

35 Pilar Franco, El amanecer de la justicia ambiental. 
medioambientales la afectación no es directa sino colectiva o indeterminada, lo que significa que no hay posibilidad de interponer esa figura jurídica en los asuntos ambientales". ${ }^{36}$

En el caso de Venezuela, la defensa de los valores ambientales encuentra puerta franca en el artículo 26 de la Constitución porque pueden ubicarse tanto como un interés personal como un interés colectivo o difuso.

El artículo en referencia dice: "Toda persona tiene derecho de acceso a los órganos de administración de justicia para hacer valer sus derechos e intereses, incluso colectivos o difusos, a la tutela efectiva de los mismos y a obtener con prontitud la decisión correspondiente.

La Constitución se pronuncia en cuanto a que "el Estado garantizará la justicia gratuita, accesible, imparcial, idónea, transparente, autónoma, independiente, responsable, equitativa y expedita, sin dilaciones indebidas, sin formalismos o reposiciones inútiles". ${ }^{37}$

En Brasil, el acceso al Poder Judicial para la defensa del medio ambiente alcanza mayores grados de eficiencia. En ese sentido, la legislación del gigante sudamericano es reconocida en la región como una de las más avanzadas.

En este mismo país, la acción pública en materia ambiental ha sido significativa en las últimas dos décadas. La Ley 6.938 de 1981 atribuyó al Ministerio Público de la Unión y a los Estados la legitimidad para defender los intereses difusos derivados de daños al ambiente. A su vez, la Ley 7.347 de 1985, que trata de la acción civil pública, amplió esa legitimidad al concederla adicionalmente a los municipios, autarquías, empresas públicas, fundaciones, sociedades de economía mixta o asociaciones, y la extendió a la defensa de los derechos de los consumidores y los bienes de valor artístico, estético, histórico, turístico y paisajístico. En 1988, esta acción pública fue consagrada en la Constitución.

Se considera que el éxito que ha tenido el Ministerio Público al intentar la acción civil se debe a las garantías establecidas en su favor en la Constitución Federal, ya que sus funcionarios gozan de prerrogativas como la inamovilidad y la irreductibilidad de sueldo. Según se ha afirmado, este instrumento legal tal vez sea el más avanzado instrumento jurídico para tratar los problemas ambientales existentes en Brasil.

En cuanto a las acciones interpuestas por la ciudadanía que resuelven las cortes y los tribunales, no solo están sirviendo para forzar el cumplimiento de la legislación ambiental por parte de las autoridades gubernamentales y del sector privado, sino que también están motivando la generación de nueva legislación ambiental a través de las sentencias proferidas. ${ }^{38}$

36 Ídem.

37 "Participación y sus mecanismos". Disponible en internet: http://www.iadb.org/sds/doc/Capitulo9.pdf

38 Ídem. 
En el contexto latinoamericano, tenemos por último el caso de Argentina, cuyo texto constitucional, como ya vimos, establece en su artículo 41 el derecho de todos los habitantes a un ambiente sano, equilibrado, apto para el desarrollo humano. Esto de por sí demuestra la existencia de un derecho humano a la preservación del ambiente, dejándose sentado que no es solo un derecho sino también un deber. Sin embargo, en materia de garantías, como las demás leyes fundamentales estudiadas, parece supeditar su plena eficacia a las decisiones de las autoridades para la protección de este derecho consagrado, lo mismo que para la preservación del patrimonio natural y cultural. De este modo, algunos autores consultados manejan el criterio de que aunque no se reglamenta nada conforme al mandato del artículo 41, este puede ser directamente aplicable, permitiendo así al ciudadano reclamar ante la justicia en busca de tutela ante las violaciones del derecho a un ambiente sano. 


\section{Conclusiones}

En resumen, podemos afirmar que doctrina y praxis proponen y emplean alternativas diversas para lograr la pretendida tutela a un ambiento sano y ecológicamente equilibrado, con mayor o menor efectividad, en dependencia de las instituciones previstas en los ordenamientos jurídicos de uno u otro país. Sin embargo, coincidimos con aquellos que sostienen que estos cauces distan mucho de ser satisfactorios y canalizarían sobre todo reacciones individualistas de carácter defensivo o reparador, ${ }^{39}$ mientras lo que se pretende sobre todo es evitar preventivamente daños y expoliaciones a bienes comunes.

En relación con el análisis comparativo tanto en el tema del reconocimiento como en el de las garantías al derecho a un ambiente sano y ecológicamente equilibrado, debemos hacer una distinción entre los textos constitucionales europeos y latinoamericanos, los que, como se ha hecho notorio, no presentan un mismo nivel de construcción dogmática constitucional referida al reconocimiento del derecho, recurriéndose a su conexión con otros derechos, como es el caso de Italia y Alemania. En otros casos, a pesar de su reconocimiento constitucional, no se lo ha elevado a la categoría de derecho fundamental, como es el caso de España, por lo que, conforme a su preceptiva constitucional, está desprovisto de las garantías reforzadas previstas para estos derechos. En cuanto al tema de las garantías, como se observa en la tabla que se anexa, la doctrina no ha logrado encaminar los cauces procesales en pos de implementar los mecanismos idóneos para la tutela judicial efectiva del derecho a un ambiente sano y ecológicamente equilibrado, empleándose, en consecuencia, las instituciones tradicionales propias del derecho procesal y los restantes mecanismos de garantías para los derechos. De hecho, como se ha visto, la tutela de los intereses colectivos ambientales en estos países solo puede realizarse por ahora con base en las técnicas ordinarias que el ordenamiento prevé, susceptibles, es cierto, de una cierta flexibilidad adaptativa en cuanto a su manejo para los fines de la defensa de dichos intereses. ${ }^{40}$

En el caso de América Latina, como sucede en otras instituciones del Derecho, parece estar a la cabeza de los cambios doctrinales que en la materia se van delineando, tanto en el reconocimiento constitucional como en su implementación como derecho fundamental. Así por ejemplo, el derecho a un ambiente sano y ecológicamente equilibrado es expresamente consagrado por las constituciones de Brasil, Colombia y Perú. Tres de estos países (Chile Ecuador y Paraguay) confieren rango de derecho fundamental al derecho a un ambiente sano, con idéntico estatus y garantías reconocidos en los derechos fundamentales consignados en la Declaración Universal de Derechos del Hombre (derecho a la vida, a la libertad, al trabajo).

Ídem.

40 Mateo Martín Ramón, Tratado de Derecho Ambiental, vol.1, Madrid, Editorial Trívium S.A., p.191. 
El enunciado consagrado por la nueva constitución de Argentina (1994) sobre el derecho de los ciudadanos a un ambiente sano puede interpretarse también como derecho fundamental. La protección del ambiente como responsabilidad de cada ciudadano es prescrita en las constituciones de Brasil, Colombia, Cuba y Perú.

En cuanto a mecanismos de garantías, igualmente los sistemas judiciales latinoamericanos exhiben los mayores logros, estrenando instituciones novedosas y otros tantos proyectos en materia procesal encaminados a la protección de este derecho a partir del acceso ciudadano a la tutela judicial efectiva. Es el caso de Brasil, con instituciones como la acción ciudadana y participación activa del Ministerio Fiscal. En igual dirección se proyectan Perú y Colombia con las denominadas acciones de cumplimiento. Además, en algunos de los casos estudiados se proyectan nuevos códigos procesales que prevén mecanismos de acceso efectivo a la jurisdicción por parte del ciudadano. 


\section{REFERENCIAS BIBLIOGRÁFICAS}

1. Carmona Lara, María Luisa, Derechos en relación con el medio ambiente, México, Instituto de investigaciones Jurídicas, UNAM, 2000. Disponible en internet: http:// www.bibliojuridica.org/libros/libro.htm?l=66

2. Caraballo Maqueira, Leonel. "El pensamiento ambiental cubano". Multimedia Derecho Ambiental Cubano, La Habana, 2006.

3. Canosa Usera, Raúl, "Protección constitucional de los derechos subjetivos ambientales", p. 127.

4. Correas, Óscar, "La teoría general del Derecho y el Derecho alternativo", en: El otro Derecho, Bogotá, ILSA, vol. 5, No. 3, 1994, pp. 61-74.

5. Cordón Moreno, Faustino, "Sobre la legitimación en Derecho Procesal", en Revista Chilena de Derecho, vol. 25, No 2, Sección Estudios, 1998.

6. De Castro Cid, Benito, Los derechos económicos, sociales y culturales: análisis a la luz de la teoría general de los derechos humanos, España, León, Universidad de León, Secretariado de Publicaciones, 1993.

7. De Oro Díaz, Aimara, "La responsabilidad administrativa ambiental como institución jurídica”. Disponible en internet: http:// www.gestiopolis.com/canales5/ger/resajuridica

8. De Oliva, Andrés y otros, "Derecho Procesal: Introducción", Madrid, Ed. Centro de Estudios Ramón Areces, 1999.

9. Di Cagno, Victorio, La protección del medio ambiente en Cuba, Edición provisional para la V Conferencia Internacional sobre Medio Ambiente y Desarrollo, La Habana, Editorial de Ciencias Sociales, 2005.

10. Fracasso, Liliana, "Planificación comunitaria y participación en los procesos de Decisión", en: Biblio 3W. Revista Bibliográfica de Geografía y Ciencias Sociales, Universidad de Barcelona, No 216, 8 de marzo de 2000.

11. Fernández Rubio, Legra, Derecho Ambiental Internacional, Ciudad de la Habana, Editorial Félix Valera, 2002.

12. Fernández Pérez, Michel, "Breves consideraciones sobre los derechos humanos en la Constitución cubana”, en: Andry Matilla Correa (Coord.) et al., Introducción al estudio del Derecho, La Habana, Félix Varela, [s.f.], pp. 169-172. 
13. Hernández Rodríguez, Odalys, "El derecho ciudadano de queja y petición frente al quehacer del Estado y la Administración Pública", en: Colectivo DE AUTORES, Memorias de la Jornada Cientifica Internacional "Homenaje a la Constitución cubana de 1976 en su XXX Aniversario", Santiago de Cuba, Ediciones UO, 2006, disponible en CD-ROM.

14. Garrido Cordovera, Lidia María, "La preservación del medio ambiente en la Constitución Nacional: La Protección y el Daño Ambiental”, en: BIDART CAMPOS G. J. y SANDLER H. R., Estudios sobre la Reforma Constitucional de 1994, Buenos Aires, Ediciones Depalma, 1995, p.127.

15. García Hernández, Gilberto, Constitución: deberes y derechos, La Habana, Ciencias Sociales, 1989.

16. Kravetz, Diego, "El control ciudadano del derecho a un medio ambiente sano en la Ciudad de Buenos Aires y su área metropolitana". Disponible en Internet: www.eclac.cl/ dmaah/noticias/paginas/7/27987/Diego_Kravetz.pdf

17. LaNDA, César, "Teoría de los derechos fundamentales". Disponible en Internet: http:// www.capje.org.pe/guia/teo.htm [consultado el 28 de noviembre de 2006].

18. Leyva, Juan, Derecho ambiental y derechos individuales, tratamiento del tema en la Reforma Constitucional de 1994, Argentina, P.1 Universidad Nacional de Lomas de Zamora.

19. Loperena Roara, Demetrio, Los derechos al medio ambiente adecuado y a su protección, Biblioteca Virtual, Universidad de País Vasco.

20. Martin Mateo, Ramón, Manual de Derecho Ambiental, segunda edición cerrada del 30 de abril de 1998, Madrid, Editorial Trívium.

21. Moreno Trujillo, E., La protección jurídico-privada del medio ambiente y la responsabilidad por su deterioro, Barcelona, J. M. Bosh Editor, 1991.

22. Muñoz Guzmán, Marco Antonio. "El medio ambiente sano como derecho humano". Disponible en Internet: http://www.scjn.gob.mx/Reforma/Foro/archivos/2743.

23. Ovalle Favela, José, "Acciones populares y acciones para la tutela de los intereses colectivos", en: Boletín Mexicano de Derecho Comparado. Disponible en Internet: http:// www.ejournal.unam.mx/boletin_mderecho/bolmex107/BMD10706

24. Pérez-Luño, A. E., Los derechos fundamentales, 5ta. edición, Madrid, Editorial Tecnos, 1993. 
25. Peña Freire, Antonio, La garantía en el Estado Constitucional de Derecho, Madrid, Ed. Trotta, 1997.

26. Pereira Campos, Santiago, "Intereses difusos y efectos de la cosa juzgada". Estudios en homenaje al profesor Enrique Vescovi, Montevideo, Fundación de Cultura Universitaria, 2000.

27. Quijano Lizarazo, Yenny Rocío, "La contaminación ambiental y la protección jurídica". Disponible en Internet: http://www.monografias.com/trabajos41/contaminacionproteccion-juridica/contaminacion-proteccion-juridica.shtml.

28. Rodríguez Pérez, Celina, "Sujetos de la relación jurídica ambiental y su legitimación". Disponible en internet: http://www.Monografias.com

29. Rodríguez Menéndez, Roberto. "Intereses y tutela constitucional", en: Revista Internauta de Práctica Jurídica, No.2, mayo-agosto 1999, p. 2.

30. Sosa, Gualberto Lucas, La defensa jurisdiccional de los intereses superindividuales y difusos. La defensa de los intereses del consumidor y del medio ambiente (análisis jurisprudencial desde Argentina). Estudios en homenaje al profesor Enrique Vescovi, Montevideo, Fundación de Cultura Universitaria, 2000.

31. Valdez Muñoz, Walter, "El derecho a un ambiente sano en el Perú". Disponible en Internet: http://www.aprodeh.org.pe/desc/informes_desc/inf98/

32. Valencia Hernández, Javier Gonzaga. "Los medios de defensa legal de la comunidad para garantizar el derecho a un ambiente sano”, en: http://www.lunazul.ucaldas.edu.co 